\title{
Acid-base fractions separated from Streblus asper leaf ethanolic extract exhibited antibacterial, antioxidant, anti- acetylcholinesterase, and neuroprotective activities
}

Anchalee Prasansuklab ${ }^{1}$, Atsadang Theerasri ${ }^{1}$, Matthew Payne ${ }^{2}$, Alison T. Ung ${ }^{2^{*}}$ and Tewin Tencomnao ${ }^{3^{*}}$

\begin{abstract}
Background: Streblus asper is a well-known plant native to Southeast Asia. Different parts of the plant have been traditionally used for various medicinal purposes. However, there is very little scientific evidence reporting its therapeutic benefits for potential treatment of Alzheimer's disease (AD). The study aimed to evaluate antibacterial, antioxidant, acetylcholinesterase (AChE) inhibition, and neuroprotective properties of $\mathrm{S}$. asper leaf extracts with the primary objective of enhancing therapeutic applications and facilitating activity-guided isolation of the active chemical constituents.

Methods: The leaves of S. asper were extracted in ethanol and subsequently fractionated into neutral, acid and base fractions. The phytochemical constituents of each fraction were analyzed using GC-MS. The antibacterial activity was evaluated using a broth microdilution method. The antioxidant activity was determined using DPPH and ABTS radical scavenging assays. The neuroprotective activity against glutamate-induced toxicity was tested on hippocampal neuronal HT22 cell line by evaluating the cell viability using MTT assay. The AChE inhibitory activity was screened by thin-layer chromatography (TLC) bioautographic method.

Results: The partition of the S. asper ethanolic leaf extract yielded the highest mass of phytochemical constitutions in the neutral fraction and the lowest in the basic fraction. Amongst the three fractions, the acidic fraction showed the strongest antibacterial activity against gram-positive bacteria. The antioxidant activities of three fractions were found in the order of acidic > basic > neutral, whereas the decreasing order of neuroprotective activity was neutral $>$ basic > acidic. TLC bioautography revealed one component in the neutral fraction exhibited anti-AChE activity. While in the acid fraction, two components showed inhibitory activity against AChE. GC-MS analysis of three fractions showed the presence of major phytochemical constituents including terpenoids, steroids, phenolics, fatty acids, and lipidic plant hormone.
\end{abstract}

(Continued on next page)

\footnotetext{
*Correspondence: Alison.Ung@uts.edu.au; tewin.t@chula.ac.th

${ }^{2}$ School of Mathematical and Physical Sciences, Faculty of Science, The

University of Technology Sydney, Sydney, NSW 2007, Australia

${ }^{3}$ Age-Related Inflammation and Degeneration Research Unit, Department of

Clinical Chemistry, Faculty of Allied Health Sciences, Chulalongkorn

University, Bangkok 10330, Thailand

Full list of author information is available at the end of the article
}

(c) The Author(s). 2018 Open Access This article is distributed under the terms of the Creative Commons Attribution 4.0 International License (http://creativecommons.org/licenses/by/4.0/), which permits unrestricted use, distribution, and reproduction in any medium, provided you give appropriate credit to the original author(s) and the source, provide a link to the Creative Commons license, and indicate if changes were made. The Creative Commons Public Domain Dedication waiver (http://creativecommons.org/publicdomain/zero/1.0/) applies to the data made available in this article, unless otherwise stated. 
(Continued from previous page)

Conclusions: Our findings have demonstrated the therapeutic potential of three fractions extracted from S. asper

leaves as a promising natural source for neuroprotective agents with additional actions of antibacterials and antioxidants, along with AChE inhibitors that will benefit in the development of new natural compounds in therapies against $A D$.

Keywords: Acid-base extraction, Streblus asper, Glutamate toxicity, HT22 cells, Neuroprotection, Alzheimer's disease, Neurodegenerative diseases

\section{Background}

Herbal medicines are gaining significant attention globally in primary health care due to its various advantages over prescribed synthetic drugs, especially in long-term usage [1-3]. Synthetic FDA approved drugs, during long-term usage, may have adverse side effects $[4,5]$, and are not cost-effective or readily affordable in under developed and developing countries [6-10]. The use of medicinal plants or plant-derived substances in the prevention and treatment of various diseases including Alzheimer's disease (AD) has been proven to be effective and is on the rise [11-15]. Two examples of plant-derived FDA approved drugs used for the treatment of $\mathrm{AD}$ are rivastigmine and galantamine, which were isolated from Physostigma venenosum and Galanthus caucasicus, respectively [16, 17]. Other promising natural products such as Huperzine A (derived from Huperzia serrata), curcumin (derived from Curcuma longa), and resveratrol (derived from Vitis vinifera) also possess excellent anti-AD activity and they are in Phase II or III clinical trials $[18,19]$. Moreover, a number of medicinal plants with antioxidant, anti-inflammatory, and anti-apoptotic effects are currently being researched as an excellent source of neuroprotective agents and/or anti-AD drugs [16, 17, 20-23].

$\mathrm{AD}$ is one of the most common neurodegenerative diseases, characterized by the progressive loss of neuronal cells in the central nervous system which eventually contributes to memory impairment. Moreover, as the result of abnormal functioning in several areas of the patient's brain in the late stage of disease, AD can be fatal and it is officially ranked as the sixth-leading cause of death in the United States (U.S.) in 2018 [24]. AD is suffered by 35-40 million patients worldwide and there is currently no proven complete cure [25]. Although the exact pathogenic mechanisms underlying $\mathrm{AD}$ remains unknown, the neurotransmitter acetylcholine and glutamate are potentially considered as therapeutic targets and have been focused since both neurotransmission systems were found aberrant in the brains of individuals with AD [26]. Drugs commonly used to treat $\mathrm{AD}$ include acetylcholinesterase (AChE) inhibitors (e.g., galantamine and donepezil) and $N$-methyl-D-aspartate (NMDA)-type glutamate receptor antagonists (e.g., memantine). Nevertheless, these drugs provide only symptomatic relief but not a cure. The debate over the therapeutic benefits versus the side effects and the financial cost of these drugs has continued for decades [27-29]. The discovery of therapeutic, cost effective $\mathrm{AD}$ drugs devoid of adverse side effects is a very active area of research [30].

Besides disturbances of neurotransmitters, oxidative stress and exacerbation of inflammatory responses have been associated with $\mathrm{AD}$ as significant contributors to neuronal damage and neurodegeneration [31-33]. Interestingly, bacterial infection is now considered as a risk or causative factor of $\mathrm{AD}$ by triggering chronic inflammation in the brain that may subsequently promote the initiation and progression of the disease [34-36]. Additionally, the presence of bacteria in the brain may play a role in the accumulation and deposition of amyloid beta $(\mathrm{A} \beta)$ peptides, the major pathological hallmark of $\mathrm{AD}$, which these peptides may be recruited to the site of infection due to their functions in innate immunity as antimicrobials [37, 38]. A dramatic reduction of cerebral $A \beta$ levels was observed when transgenic mouse model of $\mathrm{AD}$ was in the absence of gut microbiota [39] or in the prolonged shift of gut microbial composition induced by broad-spectrum combinatorial antibiotic treatment [40]. Recent evidence using next generation sequencing (NGS) analysis that observed an increase of bacterial populations in post-mortem brains from patients with $\mathrm{AD}$, also supports the involvement of bacterial infection in $\mathrm{AD}$ [41]. Hence, controlling AD-associated infections by using compounds with bactericidal or antibacterial activities was highlighted as an alternative strategy for disease prevention and treatment [34, 35, 42, 43].

Medicinal plants can be of important natural resources for novel agents that may constitute an alternative to the present drugs used in the treatment of several illnesses including AD [11]. Streblus asper Lour. is a well-known medicinal plant that belongs to family Moraceae and distributes mainly over the region of Southeast Asia. Different parts of the plant have been traditionally used for various medicinal purposes such as treatment of fever, toothache, filariasis, leprosy, snakebite, diarrhoea, piles, epilepsy, epistaxis, heart disease, urinary tract complaints, stomachache, obesity, skin diseases, wounds, and cancer $[44,45]$. It has also been used as an ingredient in a traditional Thai formula for longevity [46]. Studies on 
the crude plant extract as well as the isolated compounds have demonstrated that $S$. asper exhibits various pharmacological properties including antioxidant, anticancer [47], antimicrobial [48], antimalarial [49], anti-filarial [50], anti-inflammation [51], and anti-hepatitis B activities [52]. Moreover, the neuroprotective properties of $S$. asper leaf extracts in both in vivo and in vitro models of neurodegenerative diseases were recently reported [53, 54]. However, the active phytochemical ingredients responsible for neuroprotection have not been clearly identified. The main objective of our research is to enhance the utilization of this plant extract with the best efficacy for therapeutic applications and facilitate the clarification of its active components. This was achieved by first carrying out the fractionation of the crude ethanolic extract of $S$. asper leaves using liquid-liquid extraction based on $\mathrm{pH}$ properties of its phytochemical constituents. The resulting fractions of organic neutral, acidic, and basic components were investigated and compared to each other for their pharmacological potentials including antibacterial, antioxidant, anti-AChE, and neuroprotective activities.

\section{Methods}

\section{Chemicals and reagents}

Acetylcholinesterase from electric eel (EC 3.1.1.7, type V-S), bovine serum albumin (BSA), 1-naphthyl acetate, Fast Blue B salt, galantamine, Tris- $\mathrm{HCl}$, dimethyl sulfoxide (DMSO), Dulbecco's modified Eagle's medium (DMEM), fetal bovine serum (FBS), 2,2'-Azino-bis(3-ethylbenzothiazoline-6-sulfonic acid) diammonium salt (ABTS), and 2,2-Diphenyl-1-picrylhydrazyl (DPPH) were purchased from Sigma-Aldrich (St. Louis, MO, USA). Phosphate buffer saline (PBS) and Penicillin/ Streptomycin solution were purchased from Hyclone (Logan, Utah, USA). Trypsin-EDTA was purchased from Gibco (Waltham, MA, USA). 3-(4,5-dimetylthiazo1-2-yl)-2,5-diphenyltetrazoliumbromide (MTT) was purchased from Bio Basic (Markham, Ontario, Canada). L-ascorbic acid was purchased from Calbiochem (San Diego, CA, USA). Mueller-Hinton broth was purchased from Himedia laboratories (Mumbai, $\mathrm{MH}$, India). Other reagents used in extraction process were of analytical grade.

\section{Plant collection and identification}

Leaves of $S$. asper were collected from the Princess Maha Chakri Sirindhorn Herbal Garden (Rayong Province, Thailand). The plant was authenticated by Professor Dr. Thaweesakdi Boonkerd and deposited in the herbarium of Kasin Suvatabhandhu (Department of Botany, Faculty of Science, Chulalongkorn University, Thailand) under voucher number A013419 (BCU).

\section{Preparation of crude extract}

After collection, the ethanolic extract of $S$. asper leaves was prepared as previously described [54]. In brief, the dry powered plant material $(0.73 \mathrm{~kg})$ was soaked in $100 \%$ ethanol $(7.3 \mathrm{~L})$ with a 1:10 sample-solvent ratio for $48 \mathrm{~h}$ at room temperature (RT) in the dark with continuous shaking. The resulting liquid extract was filtered and concentrated using rotary evaporator to give $29.44 \mathrm{~g}$ of crude extract. Part of this concentrated extract was dissolved in DMSO, passed through a $0.2-\mu \mathrm{m}$ filter, and stored at $-20{ }^{\circ} \mathrm{C}$ as a stock solution for evaluating biological activities.

\section{Preparation of acid-base fractions}

For efficient acid-base extraction, crude ethanolic extract of $S$. asper leaves $(29.44 \mathrm{~g})$ was firstly dissolved in ethyl acetate (EtOAc) $(700 \mathrm{~mL})$ and partitioned with distilled water $(700 \mathrm{~mL})$. The resulting organic solution was concentrated, re-dissolved in dioxane $(200 \mathrm{~mL})$ and slowly added dropwise of distilled water $(80 \mathrm{~mL})$ while stirring continuously to induce the precipitation of chlorophyll [55]. Then, the precipitates were removed by three rounds of centrifugation (4400 rpm for $20 \mathrm{~min}$ ) with each round being followed by filtration through filter papers. The chlorophyll-removed extracts were combined, and solvents were removed to give a thick paste. The paste was used for fractionation into neutral, acidic, and basic fractions based on the method of alkaloid extraction previously used by Mungkornasawakul et al. [56], with some modifications. The procedure of acid-base extraction was summarized in Fig. 1. The crude paste was dissolved in EtOAc $(150 \mathrm{~mL})$ and extracted with $5 \%$ hydrochloric acid $(\mathrm{HCl})(700 \mathrm{~mL})$. The ethyl acetate $(\mathrm{Or}-$ ganic phase-1) layer was separated from the $5 \% \mathrm{HCl}$ (Aqueous phase-1) layer and set aside for basic extraction. The $5 \% \mathrm{HCl}$ solution was made basic ( $\mathrm{pH} 10)$ with $10 \mathrm{M}$ sodium hydroxide $(\mathrm{NaOH})$ and the resulting solution was further extracted with EtOAc $(200 \mathrm{~mL} \times 2)$. The ethyl acetate extracts were washed with saturated $\mathrm{NaCl}$ solution and dried over anhydrous potassium carbonate $\left(\mathrm{K}_{2} \mathrm{CO}_{3}\right)$. The solvent was removed to afford the basic fraction.

Simultaneously, ethyl acetate (Organic phase-1) layer was extracted with an equal volume of $0.5 \mathrm{M} \mathrm{NaOH}$ solution. The top organic layer (Organic phase-2) was separated from the aqueous $\mathrm{NaOH}$ layer (Aqueous phase-2), then washed with a saturated solution $\mathrm{NaCl}$ and dried over anhydrous sodium sulfate $\left(\mathrm{Na}_{2} \mathrm{SO}_{4}\right)$ and the solvent was removed under reduced pressure to afford the neutral fraction. Finally, the remaining the aqueous $\mathrm{NaOH}$ layer (Aqueous phase-2) was then acidified to $\mathrm{pH} 1$ with $5 \% \mathrm{HCl}$ and extracted with EtOAc $(200 \mathrm{~mL} \times 2)$. The combined ethyl acetate extracts were washed with a saturated solution $\mathrm{NaCl}$ and dried over 




anhydrous $\mathrm{Na}_{2} \mathrm{SO}_{4}$, and the solvent was removed under reduced pressure to afford the acidic fraction. Parts of three fractions obtained after acid-base extraction were dissolved in DMSO, filtered through a $0.2-\mu \mathrm{m}$ filter, and stored at $-20{ }^{\circ} \mathrm{C}$ as a stock solution for evaluating biological activities.

\section{GC-MS analysis}

Analysis of volatile chemical constituents was performed using Agilent 6890 gas chromatograph fitted with an Agilent HP-5 MS fused-silica capillary column (5\% polysilphenylene, $95 \%$ polydimethylsiloxane column, $30 \mathrm{~m} \times$ $0.25 \mathrm{~mm}$, i.d. $0.25 \mu \mathrm{m}$ film thickness), coupled to an Agilent $5973 \mathrm{~N}$ mass selective detector with electron-ionization (EI) source (Agilent Technologies, Palo Alto, CA, USA). The samples were dissolved in ethyl acetate and injected automatically in the split mode with a split ratio of 1:25 and injection volume of $1 \mu \mathrm{L}$. Helium was used as the carrier gas at a constant flow rate of $1.2 \mathrm{~mL} / \mathrm{min}$. The total run time was $10.8 \mathrm{~min}$. The column oven temperature was programmed initially at $50^{\circ} \mathrm{C}$ for $2 \mathrm{~min}$. Then, it was raised to $290{ }^{\circ} \mathrm{C}$ with a rate of $50{ }^{\circ} \mathrm{C} / \mathrm{min}$ and held at $290{ }^{\circ} \mathrm{C}$ for $4 \mathrm{~min}$. The mass spectrometer was operated with ionization energy of $70 \mathrm{eV}$, ion source temperature of $230{ }^{\circ} \mathrm{C}$, detector temperature of $150{ }^{\circ} \mathrm{C}$, and in the scan mode over the mass range of $\mathrm{m} / \mathrm{z} 40-450$. The compounds were identified by matching their recorded retention times and mass spectral patterns with the NIST mass spectral library (NIST08.L).

\section{Determination of antibacterial activity}

The antibacterial activity was determined by broth microdilution according to CLSI guidelines. The test medium was cation-adjusted Mueller-Hinton broth (CAMHB). Test Medium was used for $S$. aureus ATCC25923, B. subtilis SU5, E. coli MG1655 and P. aeruginosa PA14. Serially diluted concentrations of samples or standard antibiotic ampicillin (a positive inhibition control) were tested using a 96 well plate, which was inoculated with a bacterium cell concentration of approximately $5 \times 10^{5} \mathrm{CFU}$. The CAMHB medium plus sample without inoculum was used as a negative control. After $20 \mathrm{~h}$ of incubation at $37^{\circ} \mathrm{C}$ statically, the minimum inhibitory concentration (MIC) was defined as the lowest concentration of compound that showed 95\% cell growth inhibition, determined by measuring absorbance at $595 \mathrm{~nm}$. The experiment was performed in biological triplicates.

\section{Determination of antioxidant activity}

The antioxidant activity was evaluated in vitro using the DPPH and ABTS radical scavenging assays modified for a 96-well microtiter plate format as described previously [54]. Briefly, various concentrations of samples or 
ascorbic acid (a positive control) in absolute ethanol and the $\mathrm{DPPH} \bullet$ or ABTS • + working solution were mixed in a ratio of 9:1 $(\mathrm{v} / \mathrm{v})$ in a 96 well-plate. The working solution plus absolute ethanol was used as a negative control. The reaction mixture was incubated in the dark at RT for $15 \mathrm{~min}$ or $30 \mathrm{~min}$ and the absorbance was recorded using a microplate reader (BioTek Instruments, Winooski, VT, USA) at $517 \mathrm{~nm}$ or $734 \mathrm{~nm}$ for DPPH or ABTS assay, respectively. Radical scavenging activity was calculated as the percent inhibition of free radicals using the following equation: \% Inhibition $=100-[$ (Abs of the sample - Abs of blank) $\times 100 /$ Abs of control]. The antioxidant capacity of each sample was also compared with those of ascorbic acid (vitamin C) and was expressed as vitamin $\mathrm{C}$ equivalent antioxidant capacity (VCEAC) in mg per g of dry weight sample.

\section{Determination of anti-acetylcholinesterase activity}

The AChE inhibitory activity was screened by using thin-layer chromatography (TLC)-direct bioautographic assay adapted from Marston's method [57]. This assay is based on the activity of AChE in converting the substrate 1-naphthyl acetate to 1-naphthol, which in turn reacts with the chromogenic agent Fast Blue $B$ salt to produce a purple-coloured diazonium dye. The working solution of AChE was prepared by dissolving $1.21 \mathrm{mg}$ of lyophilized powder of AChE from electric eel in $135 \mathrm{~mL}$ of $0.05 \mathrm{M}$ Tris- $\mathrm{HCl}$ buffer at $\mathrm{pH} 7.8$ with $150 \mathrm{mg}$ of bovine serum albumin. The silica gel $F_{254}$ TLC plates (Merck, Darmstadt, Germany) were prewashed with acetone and thoroughly dried before use. Briefly, $1 \mathrm{mg}$ of each sample was dissolved in ethyl acetate (1000 ppm), $6.7 \mu \mathrm{L}(6.7 \mu \mathrm{g})$ of the solution was spotted on a pre-washed TLC plate and developed with the solvent system of hexane: ethyl acetate $(7: 3, v / \mathrm{v})$. Then, $3.3 \mu \mathrm{L}(0.3 \mu \mathrm{g})$ of galantamine solution $(0.1 \mathrm{mg} / \mathrm{mL}$, $100 \mathrm{ppm}$ ) was also applied on the plate as a positive control. After completely air-dried, the TLC plates were then saturated by spraying with the enzyme stock solution $(6.71 \mathrm{U} / \mathrm{mL})$ and incubated in a humidified chamber for $20 \mathrm{~min}$ at $37^{\circ} \mathrm{C}$. Afterwards, the enzyme activity was detected by spraying with the mixture solution containing a part of $13.8 \mathrm{mM}$ of 1-naphthyl acetate in ethanol plus four parts of $5.27 \mathrm{mM}$ of Fast Blue B salt in distilled water, onto the moist TLC plates. The presence of potential compounds with anti-AChE activity was determined as the appearance of white (clear) spot on the purple-coloured background.

\section{Cell culture and treatments}

Immortalized mouse hippocampal HT22 cell line, a kind gift from Prof. David Schubert at the Salk Institute (San Diego, CA, USA), was grown in DMEM supplemented with 10\% FBS and 1\% Penicillin/Streptomycin solution.
The cells were maintained at $37{ }^{\circ} \mathrm{C}$ in a $5 \% \mathrm{CO}_{2}$ humidified incubator and sub-cultured when they reach about 80-90\% confluency. For cell viability assay, HT22 cells were seeded onto a 96-well microtiter plate at a density of $6 \times 10^{3}$ cells per well and allowed to attach. Twenty-four hours later, the cells were incubated for additional $18 \mathrm{~h}$ with the medium in the absence or presence of $5 \mathrm{mM}$ glutamate or in the presence of $5 \mathrm{mM}$ glutamate plus various concentrations of tested extracts.

\section{Determination of cell viability}

The cell viability of HT22 cells was measured by the MTT colourimetric assay to determine the neuroprotective property of tested extracts against glutamate cytotoxicity. In the assay, untreated HT22 cells served as a negative control, while cells treated with 100\% DMSO served as a positive control. MTT was prepared as a

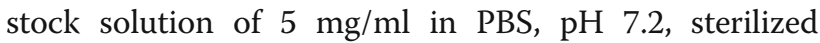
through a $0.2-\mu \mathrm{m}$ filter, and stored at $-20{ }^{\circ} \mathrm{C}$. At the end of incubation time, $20 \mu \mathrm{L}$ of MTT solution was added to each well, followed by incubation at $37{ }^{\circ} \mathrm{C}$ for $4 \mathrm{~h}$. The medium containing MTT solution was then removed and $100 \mu \mathrm{L}$ of DMSO was replaced in each well to dissolve the purple formazan crystals produced from viable cells. The absorbance was read by a microplate reader (BioTek Instruments, Winooski, VT, USA) at $550 \mathrm{~nm}$. The percentage of cell viability was calculated by the following formula: Cell viability $(\%)=[$ Abs of treated cells/ Abs of untreated cells (control)] $\times 100$.

\section{Statistical evaluation}

For antioxidant and cell viability assays, the experiments were performed at least in triplicate and the data are represented as means \pm standard deviation (SD) or means \pm standard error of the mean (SEM) as indicated in figures. The statistical analyses were performed using SPSS software version 17.0 (SPSS Inc., Chicago, IL, USA). Pearson's correlation test was conducted to evaluate the relationship between two antioxidant assays. One-way analysis of variance (ANOVA), followed by the post hoc Tukey HSD multiple comparison tests was employed to determine the differences among group means. $P$ values $<0.05$ were considered statistically significant.

\section{Results}

Extraction yields and the chemical composition of the $S$. asper fractions obtained by acid-base extraction

Acid-base extraction of $29.44 \mathrm{~g}$ of the $S$. asper ethanolic leaf extract yielded $0.158 \mathrm{~g}(0.54 \%, w / \mathrm{w})$ of basic fraction, $0.476 \mathrm{~g}(1.62 \%, \mathrm{w} / \mathrm{w})$ of acidic fraction, and $1.128 \mathrm{~g}$ $(3.83 \%, w / w)$ of neutral fraction. Figure 2 shows the color of crude leaf extract and the fractions obtained. The brownish and yellowish colors observed in the 


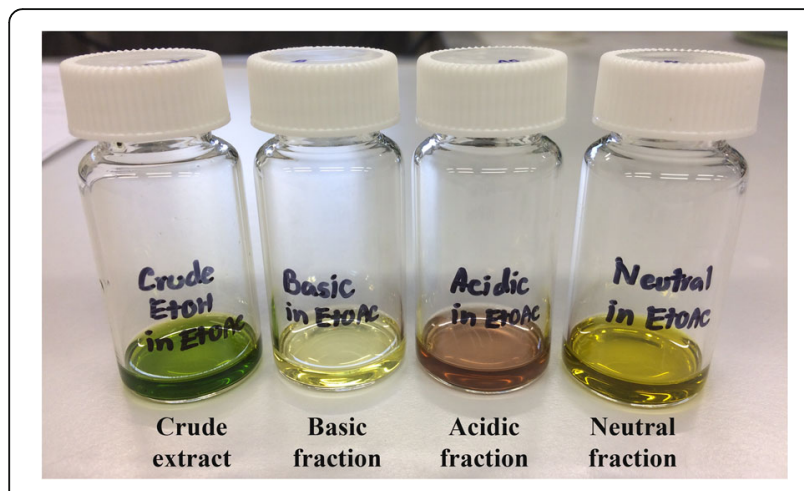

Fig. 2 Crude ethanolic extract of S. asper leaves and its acid-base fractions

acid-base fractions suggested that most of the chlorophyll (green pigment) in the leaves was successfully removed from crude leaf extract. Each fraction was further analyzed by GC-MS and tentative compounds were identified by comparing their GC retention indices and mass spectral patterns with the database at the match quality value above $80 \%$. A total of 11 tentative volatile compounds were proposed including terpenoids, steroids, phenolics, fatty acids, nitrogen-sulfur containing compounds, as well as lipidic plant hormone were listed in Table 1.

\section{Antibacterial activity of the S. asper fractions}

The antibacterial activity of the crude $S$. asper ethanolic extract and its acid-base fractions are presented in Table 2. Amongst the three fractions examined, the acidic fraction exhibited the strongest antibacterial activity against two gram-positive bacteria $S$. aureus and $B$. subtilis, with a MIC value of $125 \mu \mathrm{g} / \mathrm{mL}$. However, at the highest tested concentration of $1000 \mu \mathrm{g} / \mathrm{mL}$, none of the three fractions showed inhibition of bacterial growth at $\geq 95 \%$ against the two gram-negative bacteria $E$. coli and $P$. aeruginosa.

\section{Antioxidant capacity of the $S$. asper fractions}

The DPPH radical scavenging activities at $1 \mathrm{mg} / \mathrm{mL}$ concentration of the crude $S$. asper ethanolic extract and its acid-base fractions varied ranging from 8.94 to $17.16 \%$ (10.00 to $18.88 \mathrm{mg} \mathrm{VCEAC/g}$ dry weight), whereas their scavenging activities on ABTS radical were found much higher than those on DPPH radical in the range of 34.29 to $48.45 \%$ ( 29.02 to $39.45 \mathrm{mg} \mathrm{VCEAC} / \mathrm{g}$ dry weight) (Table 3). All the crude extract and its acid-base fractions exhibited concentration-dependent scavenging effects towards the DPPH (Fig. 3a) and ABTS radicals (Fig. 3b). Amongst all the extract and three fractions examined, the acidic fraction possessed the strongest antioxidant capacity, while the neutral fraction showed relatively weak antioxidant property based on the results from both DPPH and ABTS assays. The descending order of antioxidant potential among three isolated fractions was as acidic > basic > neutral. Pearson's correlation revealed a significant positive moderate relationship ( $r=0.7275, p=0.0014)$ between the DPPH and ABTS antioxidant activities of all tested samples (Fig. 3c).

\section{Neuroprotective activity of the $S$. asper fractions}

The neuroprotective properties of the crude $S$. asper ethanolic extract and its acid-base fractions were evaluated against glutamate toxicity in hippocampal neuronal HT22 cells. The crude extract, neutral and acidic fractions did not exhibit a noticeable cytotoxic effect on HT22 cells whose cell viabilities were above $90 \%$ following exposure to varying concentrations ranging from 1 to $50 \mu \mathrm{g} / \mathrm{mL}$ (Fig. 4a). The basic fraction became toxic to the cells when the concentration was increased above $25 \mu \mathrm{g} / \mathrm{mL}$. Treatment of HT22 cells with $5 \mathrm{mM}$ glutamate significantly reduced cell viability by approximately $80 \%$. However, co-treatment with crude extract, either neutral fraction or basic fraction significantly increased the viability of glutamate-treated HT22 cells in a dose-dependent manner, as determined using MTT assay (Fig. 4b) and examined morphologically under a phase contrast microscope (Fig. 4c). The cytotoxic effect of glutamate could be considerably restored (comparable to about $80 \%$ of the control level) in the presence of the crude extract, neutral fraction, and the basic fraction at the minimum concentration of 25,5 , and $10 \mu \mathrm{g} / \mathrm{mL}$, respectively. The acidic fraction did not show any protective effects against glutamate-induced cytotoxicity.

\section{Anti-acetylcholinesterase activity of the S. asper fractions}

TLC chromatogram of the neutral fraction isolated at least 9 visible spots of constituents under visible light (Fig. 5a) and confirmed by visualizing under short-wavelength UV radiation $(254 \mathrm{~nm})$, in which three of them were also observed by $\mathrm{KMnO}_{4}$ staining (Fig. $5 b)$. However, in the acidic fraction, there was only one spot visible under visible light (Fig. 5a), while three more spots could be only viewed under UV light, in which one of them was also observed by $\mathrm{KMnO}_{4}$ staining (Fig. $5 b)$. Using a similar solvent system to that employed in the experiment mentioned above, the AChE inhibitory properties of the neutral and acidic fractions were further evaluated on TLC plates by the bioautographic method and are shown in Fig. 5c. In this assay, the white spot of inhibition on a dark purple background of the plate represented the chemical components with AChE inhibitory activity. A total of three chemical constituents corresponding to AChE inhibitory activity in the neutral and acidic fractions were found. TLC bioautogram of the neutral fraction showed one spot of inhibition with 
Table 1 GC-MS analysis of the volatile components presented in the S. asper fractions

\begin{tabular}{|c|c|c|c|c|}
\hline Fraction & Retention time (min) & Relative area (\%) & Tentative identification & Match quality (\%) \\
\hline \multirow[t]{9}{*}{ Neutral } & 6.111 & 2.6 & Dihydroactinidiolide & 94 \\
\hline & 6.548 & 5.5 & Cadalene & 80 \\
\hline & 6.696 & 11.7 & n.i. & - \\
\hline & 7.124 & 7.0 & Benzothiazole, 2-(2-hydroxyethylthio)- & 99 \\
\hline & 7.466 & 5.9 & n.i. & - \\
\hline & 8.370 & 9.4 & Cholest-14-en-3-ol, 4-methyl-, (3.beta.,4.alpha.,5.alpha.)- & 93 \\
\hline & 8.417 & 10.8 & n.i. & - \\
\hline & 8.612 & 7.4 & 2,4-Bis(1-phenylethyl)phenol & 86 \\
\hline & 10.072 & 7.3 & n.i. & - \\
\hline \multirow[t]{12}{*}{ Acidic } & 5.531 & 0.6 & 4-Hydroxybenzaldehyde & 91 \\
\hline & 5.683 & 0.2 & Vanillin & 96 \\
\hline & 6.477 & 0.3 & $(+/-)$-Jasmonic acid & 95 \\
\hline & 6.543 & 3.6 & Cadalene & 83 \\
\hline & 6.686 & 3.1 & n.i. & - \\
\hline & 7.010 & 2.2 & Palmitic acid & 99 \\
\hline & 7.114 & 6.9 & Benzothiazole, 2-(2-hydroxyethylthio)- & 98 \\
\hline & 7.457 & 12.6 & Linolenic acid & 99 \\
\hline & 7.485 & 8.5 & n.i. & - \\
\hline & 8.355 & 6.8 & Cholest-14-en-3-ol, 4-methyl-, (3.beta.,4.alpha.,5.alpha.)- & 91 \\
\hline & 8.398 & 7.2 & n.i. & - \\
\hline & 8.593 & 5.8 & 2,4-Bis(1-phenylethyl)phenol & 93 \\
\hline \multirow[t]{10}{*}{ Basic } & 5.421 & 1.6 & n.i. & - \\
\hline & 6.543 & 2.2 & Phenol, 2-(1-phenylethyl)- & 91 \\
\hline & 6.686 & 30.1 & n.i. & - \\
\hline & 6.762 & 4.9 & n.i. & - \\
\hline & 7.109 & 6.0 & Benzothiazole, 2-(2-hydroxyethylthio)- & 99 \\
\hline & 7.295 & 8.2 & n.i. & - \\
\hline & 7.471 & 12.4 & n.i. & - \\
\hline & 8.350 & 4.2 & n.i. & - \\
\hline & 8.398 & 4.6 & n.i. & - \\
\hline & 8.588 & 3.3 & Phenol, 2,4-bis(1-phenylethyl)- & 91 \\
\hline
\end{tabular}

n.i. Not identified

Table 2 Antibacterial activities of crude ethanolic extract of S. asper leaves and its fractions against a range of microorganisms determined by the broth microdilution method

\begin{tabular}{|c|c|c|c|c|}
\hline \multirow[t]{2}{*}{ Microorganisms } & \multicolumn{4}{|c|}{ Minimum inhibitory concentration (MIC) in $\mu \mathrm{g} / \mathrm{mL}$} \\
\hline & Crude extract & Neutral fraction & Acidic fraction & Basic fraction \\
\hline \multicolumn{5}{|l|}{ Gram-positive bacteria } \\
\hline Staphylococcus aureus (ATCC25923) & 1000 & 1000 & 125 & 1000 \\
\hline Bacillus subtilis (SU5) & 1000 & 250 & 125 & 500 \\
\hline \multicolumn{5}{|l|}{ Gram-negative bacteria } \\
\hline Escherichia coli (MG1655) & $>1000$ & $>1000$ & $>1000$ & $>1000$ \\
\hline Pseudomonas aeruginosa (PA14) & $>1000$ & $>1000$ & $>1000$ & $>1000$ \\
\hline
\end{tabular}

MIC values are the lowest concentrations at which at least $95 \%$ bacterial growth reduction The tested concentration of samples ranged from 125 to $1000 \mu \mathrm{g} / \mathrm{mL}$ 
Table 3 Antioxidant capacities of the crude ethanolic extract of S. asper leaves and its fractions determined by the DPPH and ABTS scavenging assays

\begin{tabular}{lllll}
\hline Sample & $\begin{array}{l}\text { DPPH scavenging assay } \\
\text { \%Radical Scavenging activity (of 1 mg/ } \\
\text { mL sample) }\end{array}$ & \begin{tabular}{l} 
ABTS scavenging assay \\
\cline { 4 - 5 } \\
mg VCEAC/g dry weight
\end{tabular} & $\begin{array}{l}\text { \%Radical Scavenging activity (of 1 mg/ } \\
\mathrm{mL} \text { sample) }\end{array}$ & $\begin{array}{l}\mathrm{mg} \text { VCEAC/g dry weight } \\
\text { sample }\end{array}$ \\
\hline $\begin{array}{l}\text { Crude } \\
\text { extract }\end{array}$ & $16.58 \pm 1.33^{\mathrm{a}}$ & $18.37 \pm 1.25^{\mathrm{a}}$ & $37.69 \pm 1.81^{\mathrm{a}}$ & $31.52 \pm 1.63^{\mathrm{a}}$ \\
$\begin{array}{l}\text { Neutral } \\
\text { fraction }\end{array}$ & $8.94 \pm 0.78^{\mathrm{b}}$ & $10.63 \pm 1.38^{\mathrm{b}}$ & $34.29 \pm 1.56^{\mathrm{b}}$ & $29.02 \pm 1.43^{\mathrm{b}}$ \\
$\begin{array}{l}\text { Acidic } \\
\text { fraction }\end{array}$ & $17.16 \pm 1.74^{\mathrm{a}}$ & $18.88 \pm 1.39^{\mathrm{a}}$ & $48.45 \pm 1.55^{\mathrm{c}}$ & $39.45 \pm 1.43^{\mathrm{c}}$ \\
Basic fraction & $8.94 \pm 1.62^{\mathrm{b}}$ & $10.00 \pm 0.77^{\mathrm{b}}$ & $39.23 \pm 0.66^{\mathrm{a}}$ & $32.66 \pm 0.84^{\mathrm{a}}$
\end{tabular}

Results are expressed as mean \pm SD of at least three replicates

Different superscript letters in the same column indicate a significant difference between the means by one-way ANOVA ( $p<0.05)$ and the same letter indicates that there is no statistical difference

$\mathrm{R}_{\mathrm{f}}$ value of 0.44 and positive staining for $\mathrm{KMnO}_{4}$ (Fig. $5 \mathrm{~b}$ and $\mathrm{c}$ ). TLC bioautogram of the acidic fraction showed two spots of inhibition with $R_{f}$ values of 0.15 and 0.55 . The spot with $R_{\mathrm{f}} 0.15$ was also positively stained with $\mathrm{KMnO}_{4}$ (Fig. $5 \mathrm{~b}$ and c).

\section{Discussion}

The current available medications can only reduce the severity of $\mathrm{AD}$ in certain patient groups, since there has been no complete cure known for it. Importantly, AD can be fatal and is now recognized as one of the major global health problems [24]. Therefore, its prevalence continues to rise rapidly, along with the burden on public healthcare costs. This has a long-term impact on the socio-economic development of the developing countries. In challenging this difficult situation, a number of researchers have put a considerable effort for decades in search of alternative treatment methods. Research in the
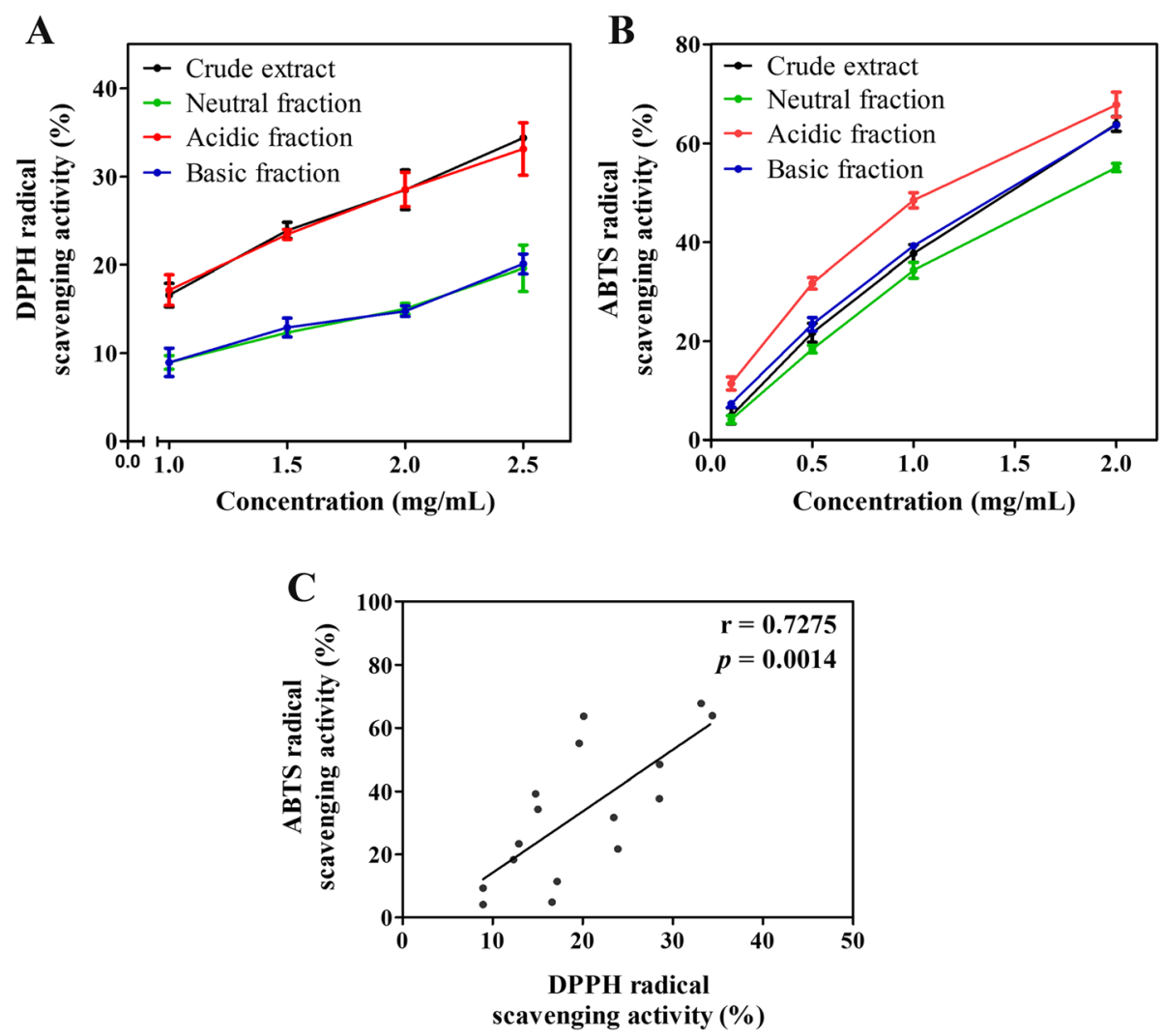

Fig. 3 The dose-response scavenging effects of the crude ethanolic extract of S. asper leaves and its fractions on a DPPH and $\mathbf{b}$ ABTS free radicals. Data are expressed as means \pm SD of 3-7 replicates. c Pearson's correlation analysis between DPPH and ABTS scavenging activities based on mean values of all samples analyzed 

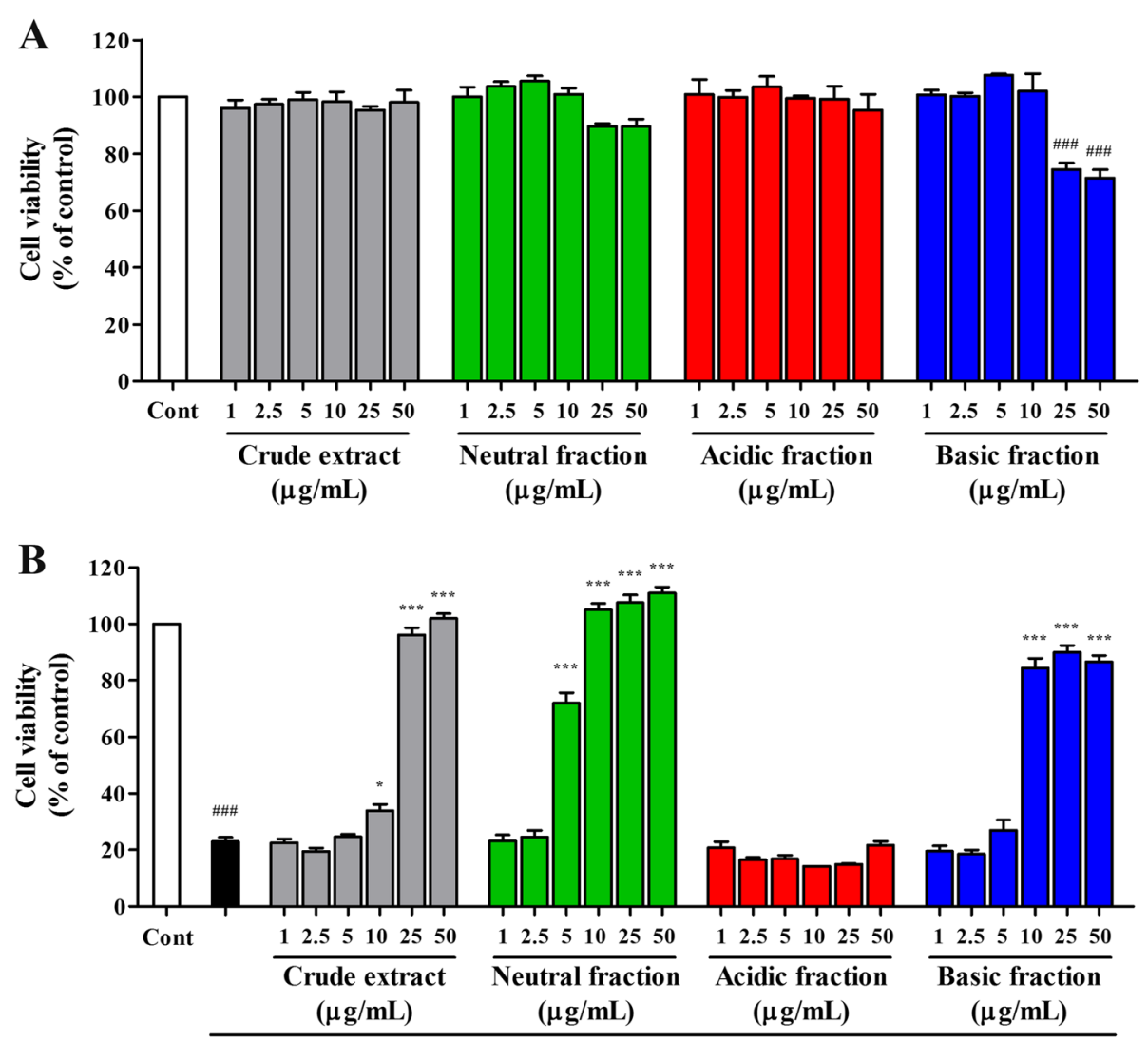

Glutamate (5mM)

C

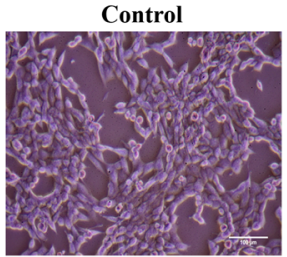

$5 \mathrm{mM}$ Glu


5mM Glu +

$5 \mathrm{mM}$ Glu + Neutral $10 \mu \mathrm{g} / \mathrm{mL}$ Acidic $10 \mu \mathrm{g} / \mathrm{mL}$

$5 \mathrm{mM} \mathrm{Glu}+$

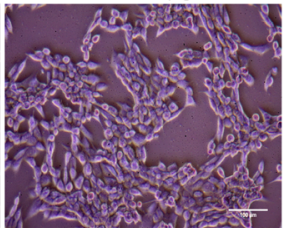

$5 \mathrm{mM} \mathrm{Glu}+$

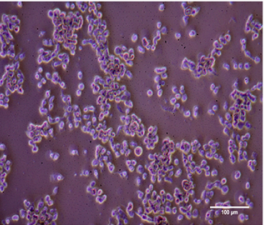
Basic $10 \mu \mathrm{g} / \mathrm{mL}$

$5 \mathrm{mM} \mathrm{Glu}+$

Neutral 25 $\mu \mathrm{g} / \mathrm{mL}$

$5 \mathrm{mM}$ Glu + Acidic $25 \mu \mathrm{g} / \mathrm{mL}$

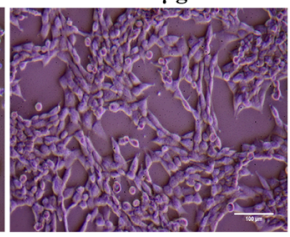

Crude 25 $\mu \mathrm{g} / \mathrm{mL}$
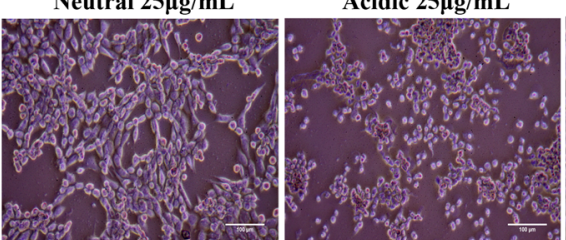

Glu +

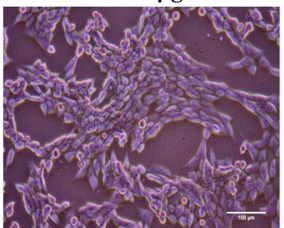

Basic 25 $\mu \mathrm{g} / \mathrm{mL}$ 
(See figure on previous page.)

Fig. 4 Protective effects of the crude ethanolic extract of S. asper leaves and its fractions against glutamate-induced neuronal cell death. a Relative MTT viability of HT22 cells exposed to various concentrations of extracts. ${ }^{\# \# \#} P=8.8 \times 10^{-5}$ for $25 \mu \mathrm{g} / \mathrm{mL}$ and ${ }^{\# \# \#} P=7.5 \times 10^{-6}$ for $50 \mu \mathrm{g} /$ $\mathrm{mL}$ of basic fraction vs. control. b Relative MTT viability of HT22 cells exposed to glutamate alone or glutamate combined with different concentrations of extracts. ${ }^{\# \# \#} P=2.9 \times 10^{-11}$ vs. control; ${ }^{*} P=3.1 \times 10^{-2}$ and ${ }^{* * *} P=2.9 \times 10^{-11}$ vs. glutamate-treated cells. c Representative morphological images at $5 \mathrm{X}$ magnification (scale bar $=100 \mu \mathrm{m}$ ) of untreated HT22 cells (control), or cells treated with glutamate alone, or with glutamate plus crude extract or fractions at 1 and $10 \mu \mathrm{g} / \mathrm{mL}$. Data are expressed as means \pm SEM of 4 independent experiments with 2-3 replicates each

field of herbal medicines has attracted much attention in recent years, as it is believed to have advantages over modern synthetic medicines with regard to efficacy, safety, and cost for treatment of various medical problems. In Southeast-Asian countries, $S$. asper is a well-known medicinal plant that has been traditionally used for a variety of illness conditions despite limited scientific evidence [44-46]. Interestingly, the ethanolic leaf extracts of this plant have shown pharmacological properties including antibacterial, neuroprotective, and cognitive-improving effects that can be beneficial for the treatment of $\mathrm{AD}[48,53,54]$. However, the active constituents responsible for those different activities have not been clearly identified. In this study, the $S$. asper leaf ethanolic extract was fractionated into fractions based on $\mathrm{pH}$ properties and further evaluated for their antibacterial, antioxidant, anti- $\mathrm{AChE}$, and neuroprotective activities. These biological activities could enhance the therapeutic applications and facilitating activity-guided isolation of active compounds of the S. asper extract in the near future.

S. asper is commonly used to treat skin infections (e.g. boils, leprosy, and wounds) and has beneficial role for oral health and hygiene (e.g. relief of toothache, antigingivatis, and strengthening teeth and gum) [44]. The bacterial species, which are most frequently found associated with $\mathrm{AD}$, are commonly found in oral cavities such as spirochetes [42] and actinobacteria [41], thus it is tempting us to investigate the antibacterial properties of this plant. In this study, the crude ethanolic extract was found to inhibit cell growth of gram-positive bacteria, S. aureus and B. subtilis. This effect was more profound when the extract was fractionated to the acidic fraction (MIC of $125 \mu \mathrm{g} / \mathrm{mL}$ ) with at least eight-fold higher than to ethanol crude extract. Neither the ethanol extract nor acid-base fractions inhibit the growth of gram-negative bacteria, E. coli and P. aeruginosa. Previous work by Wongkam et al. on the crude $50 \%$ ethanolic extract, reported no antibacterial activity when tested on the bacteria strains used in our study. Their study instead showed weak MIC and MBC of $1.93 \mathrm{mg} / \mathrm{mL}$ against Streptococcus mutans, Porphyromonas gingivalis, and Actinobacillus actinomycetemcomitans; bacteria that are commonly associated with dental caries and gingivitis $[48,58,59]$. The source of plant collection and the percentage of ethanol used for extraction may be the critical factors for the different findings. Although gram-negative bacteria are generally more harmful, some
A

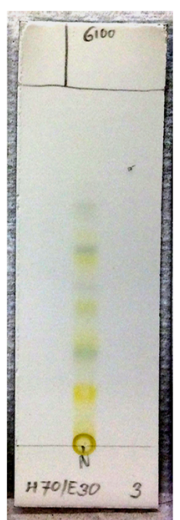

Neutral

fraction

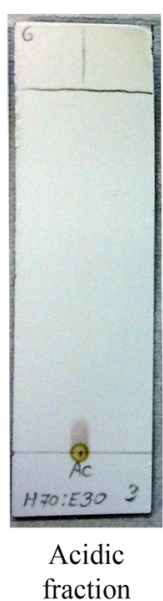

B

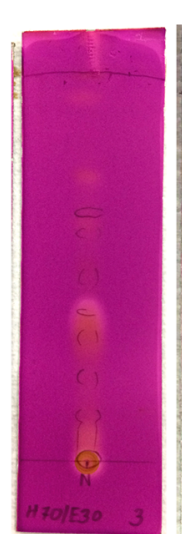

Neutral

fraction

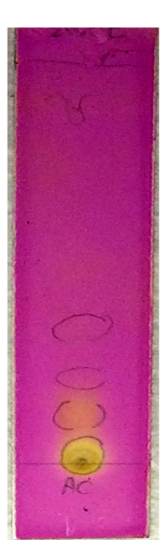

Acidic

fraction
C

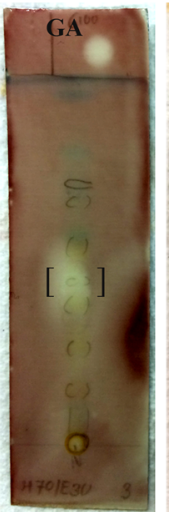

Neutral

fraction

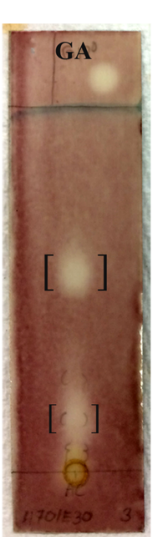

Acidic fraction

Fig. 5 Anti-AChE activities of neutral and acidic fractions obtained from S. asper leaves. TLC chromatograms of neutral and acidic fractions (at $6.7 \mathrm{\mu g}$ application) in a solvent system of hexane:ethyl acetate $(7: 3, \mathrm{~V} / \mathrm{V})$ were observed $\mathbf{a}$ under visible light, $\mathbf{b}$ by staining with $\mathrm{KMnO}_{4}$, and $\mathbf{c}$ by bioautographic method for screening on AChE inhibitory activity, where white spots against the dark background represent the inhibition. Galantamine (GA) was used as a positive control at $0.3 \mu \mathrm{g}$. Brackets indicate AChE inhibiting constituents 
of the gram-positive bacteria can also be pathogenic in humans. S. aureus is one of the most common causes of skin and nosocomial infections as well as other infections at various sites of the body (e.g. bone, joint, lung, and gastrointestinal tract) with symptoms ranging from minor to life-threatening [60]. Here, our study provides supporting evidence for the use of acidic fraction from SA leaves to treat gram-positive bacterial infections particularly caused by $S$. aureus. Moreover, the promising antibacterial activity of the acidic fraction relative to other fractions could be contributed by the action of its major volatile component, linolenic acid (Table 1, [54]). It has been demonstrated that long-chain unsaturated fatty acids including linolenic acid exerted highly potent activity against gram-positive bacteria [61-64].

Free radicals are groups of atoms with an unpaired number of electrons residing in the outermost shell. The majority of free radicals are generated from oxygen molecules and called reactive oxygen species (ROS). Once formed in excess, these highly reactive free radicals can cause damage, in the process called oxidative stress, to important cellular components such as lipids, proteins and nucleic acids, subsequently, alter the structures and functions that are associated with various human diseases including $\mathrm{AD}$ [65]. In general, these detrimental effects of free radicals can be counterbalanced by antioxidants, which are naturally derived from plants. $S$. asper can be considered as an alternative source for antioxidants since this plant has been shown promising antioxidant properties in both in vitro and in vivo [54, 6670]. In line with the previous reports, our present study also revealed the antioxidant properties, like free radical scavenging, in $S$. asper leaf extracts. The ethanol crude extract, neutral, acidic and basic fractions exhibited relatively two- to four-fold higher activities in the ABTS assay than in the DPPH assay and the percentage of scavenging activities determined in both assays were moderately correlated $(r=0.73)$. The slight difference in results could be probably due to the distinct solubility of tested substances in water, as hydrophilic antioxidants were found better reflected by the ABTS than the DPPH assay [71, 72]. Interestingly, after fractionation of crude ethanolic leaf extract, the scavenging activities on DPPH and ABTS radicals were found significantly higher in the acidic fraction when compared to the crude extract and other fractions, while the neutral fraction showed the lowest antioxidant capacity in both assays. These findings suggest that the components with antiradical activity in $S$. asper leaves are majorly in acidic and water-soluble forms. Nevertheless, the DPPH and ABTS radicals used in this study are uncommonly found in the human body, the antioxidant capacity has to be further investigated using ROS, which are produced as by-products during cellular metabolism such as superoxide radicals
$\left(\mathrm{O}_{2} \bullet-\right)$, hydrogen peroxide $\left(\mathrm{H}_{2} \mathrm{O}_{2}\right)$, or highly reactive hydroxyl radicals $(\mathrm{OH} \bullet)$ for a better idea.

In an effort to develop a more effective treatment for $A D$, several studies have been searching for new therapeutic targets underlying the disease pathology. Apart from the cholinergic hypothesis that has been proposed in the etiology of $\mathrm{AD}$ for several decades [73], growing evidence links oxidative glutamate toxicity (or oxytosis) to AD by supporting that glutamate-induced neuronal cell death via non-receptor-mediated oxidative toxicity pathway involves in the pathogenic mechanism of neurodegeneration [74-76]. Hence, targeting towards the glutamate-mediated oxidative toxicity pathway may offer a new approach for treating AD as well as other neurodegenerative diseases. In accordance with our previous results, the present study demonstrated that crude ethanolic extract from $S$. asper leaves exerted neuroprotective property against glutamate-induced HT22 neuronal cell death [54]. This protective activity was also found higher following fractionation of crude ethanolic leaf extract. The strongest protective activity against glutamate toxicity in HT22 cells was observed in the neutral fraction, wherein the minimum concentration showing recovery of $80 \%$ cell viability was five-fold lower than that of the crude extract. Interestingly, TLC bioautography also suggested that neutral fraction contains at least one compound with $\mathrm{AChE}$ inhibitory activity with minimum inhibitory concentration requirement of approximately $6.7 \mu \mathrm{g}$. Therefore, this finding indicates that neutral fraction can be further developed as a potential multi-target agent for $\mathrm{AD}$ treatment. However, due to the weak antiradical activity of neutral fraction, it may exert neuroprotective capacity against glutamate-induced oxidative damage via other antioxidative mechanisms. For instance, induction of nuclear translocation of nuclear factor erythroid 2-related factor 2 (Nrf2) is a protective pathway proposed in our previous work [54].

\section{Conclusions}

Our findings have demonstrated the therapeutic potential of three acid-base fractions extracted from the leaf part of $S$. asper as promising natural source for neuroprotective agents with additional actions of antibacterials and antioxidants, along with AChE inhibitors. Further studies should aim to isolate bioactive substances from neutral and acidic fractions and identify the mechanisms underlying their actions, which can be used to develop new natural agents as therapeutic drugs for the treatment of $\mathrm{AD}$.

\section{Abbreviations}

ABTS: 2,2'-Azino-bis(3-ethylbenzothiazoline-6-sulfonic acid) diammonium salt; AChE: Acetylcholinesterase; AD: Alzheimer's disease; DPPH: 2,2-Diphenyl-1picrylhydrazyl; GC-MS: Gas chromatography-mass spectrometry; MIC: Minimum inhibitory concentration; MTT: 3-(4,5-dimetylthiazol-2-yl)-2,5- 
diphenyltetrazoliumbromide; NMDA: N-methyl-D-aspartate; Nrf2: Nuclear factor erythroid 2-related factor 2; TLC: Thin-layer chromatography;

VCEAC: Vitamin C equivalent antioxidant capacity

\section{Acknowledgements}

The authors are very grateful to the Princess Maha Chakri Sirindhorn Herbal Garden (Rayong Province, Thailand) for providing plant material, to Prof. David Schubert (The Salk Institute, San Diego, CA, USA) for his generous gift of HT22 cells and to Dr. Prasanth M. lyer for his kind help in language editing. We are grateful to the Faculty of Science, UTS for providing support to this project.

\section{Funding}

This work was financially supported by the 90th anniversary of Chulalongkorn University fund. AP was supported by a Chulalongkorn University Graduate Scholarship to commemorate the 72nd Anniversary of His Majesty King Bhumibol Adulyadej, an Overseas Research Experience Scholarship for Graduate Student by the Graduate School, Chulalongkorn University, and a Grant for Joint Funding, Ratchadaphiseksomphot Endowment Fund. The study conducted by AP for 6 months in School of Mathematical and Physical Sciences, UTS was supported by the University of Technology of Sydney.

\section{Availability of data and materials}

The datasets used and/or analyzed during the current study available from the corresponding author on reasonable request.

\section{Authors' contributions}

$\mathrm{AU}$ and $T T$ designed the research study, supervised, and corrected the manuscript. AP, AT, and MP performed the experiments. AP analyzed data and wrote the manuscript. All authors approved the final version of the manuscript.

\section{Ethics approval and consent to participate}

Not applicable.

\section{Consent for publication}

Not applicable.

\section{Competing interests}

The authors declared that they have no competing interests.

\section{Publisher's Note}

Springer Nature remains neutral with regard to jurisdictional claims in published maps and institutional affiliations.

\section{Author details}

'Program in Clinical Biochemistry and Molecular Medicine, Department of Clinical Chemistry, Faculty of Allied Health Sciences, Chulalongkorn University, Bangkok 10330, Thailand. ${ }^{2}$ School of Mathematical and Physical Sciences, Faculty of Science, The University of Technology Sydney, Sydney, NSW 2007, Australia. ${ }^{3}$ Age-Related Inflammation and Degeneration Research Unit, Department of Clinical Chemistry, Faculty of Allied Health Sciences, Chulalongkorn University, Bangkok 10330, Thailand.

Received: 3 May 2018 Accepted: 12 July 2018

\section{Published online: 24 July 2018}

\section{References}

1. Ubel PA, Abernethy AP, Zafar SY. Full disclosure--out-of-pocket costs as side effects. N Engl J Med. 2013;369(16):1484-6.

2. Wang Z, Liu X, Ho RL, Lam CW, Chow MS. Precision or personalized medicine for Cancer chemotherapy: is there a role for herbal medicine. Molecules. 2016;21(7)

3. Augustine NR, Madhavan G, Nass SJ (Eds). Committee on Ensuring Patient Access to Affordable Drug Therapies; Board on Health Care Services; Health and Medicine Division; National Academies of Sciences, Engineering, and Medicine, Making Medicines Affordable A National Imperative. Washington (DC): National Academies Press (US); 2017.

4. Kroger E, Mouls M, Wilchesky M, Berkers M, Carmichael PH, van Marum R, et al. Adverse drug reactions reported with cholinesterase inhibitors: an analysis of 16 years of individual case safety reports from VigiBase. Ann Pharmacother 2015; 49(11):1197-1206.

5. Shehab N, Patel PR, Srinivasan A, Budnitz DS. Emergency department visits for antibiotic-associated adverse events. Clin Infect Dis. 2008;47(6):735-43.

6. Cummings JL, Morstorf T, Zhong K. Alzheimer's disease drug-development pipeline: few candidates, frequent failures. Alzheimers Res Ther. 2014;6(4):37.

7. Hung SY, Fu WM. Drug candidates in clinical trials for Alzheimer's disease. J Biomed Sci. 2017;24(1):47.

8. Ventola CL. The antibiotic resistance crisis: part 1: causes and threats. P T. 2015;40(4):277-83.

9. Ventola $\mathrm{CL}$. The antibiotic resistance crisis: part 2: management strategies and new agents. P T. 2015;40(5):344-52.

10. Rex JH, Talbot GH, Goldberger MJ, Eisenstein BI, Echols RM, Tomayko JF, et al. Progress in the fight against multidrug-resistant Bacteria 2005-2016: modern noninferiority trial designs enable antibiotic development in advance of epidemic bacterial resistance. Clin Infect Dis 2017; 65(1):141-146.

11. Newman DJ, Cragg GM. Natural products as sources of new drugs from 1981 to 2014. J Nat Prod. 2016;79(3):629-61.

12. Owen L, Laird K. Synchronous application of antibiotics and essential oils: dual mechanisms of action as a potential solution to antibiotic resistance. Crit Rev Microbiol. 2018:1-22.

13. Akhondzadeh S, Abbasi SH. Herbal medicine in the treatment of Alzheimer's disease. Am J Alzheimers Dis Other Demen. 2006;21(2):113-8.

14. Tian J, Shi J, Zhang X, Wang Y. Herbal therapy: a new pathway for the treatment of Alzheimer's disease. Alzheimers Res Ther. 2010;2(5):30.

15. Yang WT, Zheng XW, Chen S, Shan CS, Xu QQ, Zhu JZ, et al. Chinese herbal medicine for Alzheimer's disease: clinical evidence and possible mechanism of neurogenesis. Biochem Pharmacol 2017; 141:143-155.

16. Syad AN, Devi K. Botanics: a potential source of new therapies for Alzheimer's disease. Botanics. 2014;4:11-6.

17. Kumar A, Singh A, Aggarwal A. Therapeutic potentials of herbal drugs for Alzheimer's disease - an overview. Indian J Exp Biol. 2017;55:63-73.

18. Zangara A. The psychopharmacology of huperzine a: an alkaloid with cognitive enhancing and neuroprotective properties of interest in the treatment of Alzheimer's disease. Pharmacol Biochem Behav. 2003;75(3):675-86.

19. Mazzanti G, Di Giacomo S. Curcumin and resveratrol in the Management of Cognitive Disorders: what is the clinical evidence? Molecules. 2016;21:9.

20. Suk K. Regulation of neuroinflammation by herbal medicine and its implications for neurodegenerative diseases. A focus on traditional medicines and flavonoids. Neurosignals. 2005;14(1-2):23-33.

21. Hugel HM. Brain food for Alzheimer-free ageing: focus on herbal medicines. Adv Exp Med Biol. 2015;863:95-116.

22. Abushouk Al, Negida A, Ahmed H, Abdel-Daim MM. Neuroprotective mechanisms of plant extracts against MPTP induced neurotoxicity: future applications in Parkinson's disease. Biomed Pharmacother. 2017;85:635-45.

23. Dey A, Bhattacharya R, Mukherjee A, Pandey DK. Natural products against Alzheimer's disease: Pharmaco-therapeutics and biotechnological interventions. Biotechnol Adv. 2017;35(2):178-216.

24. Alzheimer's Association: 2018 Alzheimer's Disease Facts and Figures. https:// www.alz.org/media/HomeOffice/Facts\%20and\%20Figures/facts-and-figures. pdf. Accessed 18 July 2018.

25. Biran Y, Masters CL, Barnham KJ, Bush Al, Adlard PA. Pharmacotherapeutic targets in Alzheimer's disease. J Cell Mol Med. 2009;13(1):61-86.

26. Wenk GL. Neuropathologic changes in Alzheimer's disease: potential targets for treatment. J Clin Psychiatry. 2006;67(Suppl 3):3-7.

27. Lanctot KL, Rajaram RD, Herrmann N. Therapy for Alzheimer's disease: how effective are current treatments? Ther Adv Neurol Disord. 2009;2(3):163-80.

28. Casey DA, Antimisiaris D, O'Brien J. Drugs for Alzheimer's disease: are they effective? P T. 2010;35(4):208.

29. Bond M, Rogers G, Peters J, Anderson R, Hoyle M, Miners A, et al. The effectiveness and cost-effectiveness of donepezil, galantamine, rivastigmine and memantine for the treatment of Alzheimer's disease (review of technology appraisal no. 111): a systematic review and economic model. Health Technol Assess. 2012;16(21):1-470.

30. Cacabelos R. Have there been improvements in Alzheimer's disease drug discovery over the past 5 years? Expert Opin Drug Discov. 2018;13(6):523-38.

31. Agostinho P, Cunha RA, Oliveira C. Neuroinflammation, oxidative stress and the pathogenesis of Alzheimer's disease. Curr Pharm Des. 2010;16(25):2766-78.

32. Zotova E, Nicoll JA, Kalaria R, Holmes C, Boche D. Inflammation in Alzheimer's disease: relevance to pathogenesis and therapy. Alzheimers Res Ther. 2010;2(1):1. 
33. Zhao Y, Zhao B. Oxidative stress and the pathogenesis of Alzheimer's disease. Oxidative Med Cell Longev. 2013;2013:316523.

34. Bibi F, Yasir M, Sohrab SS, Azhar El, Al-Qahtani MH, Abuzenadah AM, et al. Link between chronic bacterial inflammation and Alzheimer disease. CNS Neurol Disord Drug Targets 2014; 13(7):1140-1147.

35. Itzhaki RF, Lathe R, Balin BJ, Ball MJ, Bearer EL, Braak H, et al. Microbes and Alzheimer's disease. J Alzheimers Dis 2016; 51(4):979-984.

36. Miklossy J, McGeer PL. Common mechanisms involved in Alzheimer's disease and type 2 diabetes: a key role of chronic bacterial infection and inflammation. Aging (Albany NY). 2016;8(4):575-88.

37. Soscia SJ, Kirby JE, Washicosky KJ, Tucker SM, Ingelsson M, Hyman B, et al. The Alzheimer's disease-associated amyloid beta-protein is an antimicrobial peptide. PLoS One 2010; 5(3):e9505.

38. Kumar DK, Choi SH, Washicosky KJ, Eimer WA, Tucker S, Ghofrani J, et al. Amyloid-beta peptide protects against microbial infection in mouse and worm models of Alzheimer's disease. Sci Transl Med 2016; 8(340):340ra372.

39. Harach T, Marungruang N, Duthilleul N, Cheatham V, Mc Coy KD, Frisoni G, et al. Reduction of Abeta amyloid pathology in APPPS1 transgenic mice in the absence of gut microbiota. Sci Rep 2017; 7:41802.

40. Minter MR, Hinterleitner R, Meisel M, Zhang C, Leone V, Zhang X, et al. Antibiotic-induced perturbations in microbial diversity during post-natal development alters amyloid pathology in an aged APPSWE/PS1DeltaE9 murine model of Alzheimer's disease. Sci Rep 2017; 7(1):10411.

41. Emery DC, Shoemark DK, Batstone TE, Waterfall CM, Coghill JA, Cerajewska $T L$, et al. $16 \mathrm{~S}$ rRNA next generation sequencing analysis shows Bacteria in Alzheimer's post-mortem brain. Front Aging Neurosci 2017; 9:195.

42. Allen HB. Alzheimer's disease: assessing the role of spirochetes, biofilms, the immune system, and amyloid-beta with regard to potential treatment and prevention. J Alzheimers Dis. 2016;53(4):1271-6.

43. Hefendehl JK, LeDue J, Ko RW, Mahler J, Murphy TH, MacVicar BA. Mapping synaptic glutamate transporter dysfunction in vivo to regions surrounding Abeta plaques by iGluSnFR two-photon imaging. Nat Commun. 2016;7:13441.

44. Rastogi S, Kulshreshtha DK, Rawat AK. Streblus asper Lour. (Shakhotaka): a review of its chemical, pharmacological and Ethnomedicinal properties. Evid Based Complement Alternat Med. 2006;3(2):217-22.

45. Verma NK, Singh SP, Singh AP, Singh R, Rai PK, Tripathi AK. A brief study on Strebulus asper L.-a review. RJP. 2015;1(2):65-71.

46. Luanchoy $S$, Tiangkul $S$, Wongkrajang $Y$, Temsiririrkkul $R$, Peungvicha $P$, Nakornchai S. Antioxidant activity of a Thai traditional formula for longevity. Mahidol J Pharm Sci. 2014;41:1-5.

47. Ren Y, Chen W-L, Lantvit DD, Sass EJ, Shriwas P, Ninh TN, et al. Cardiac glycoside constituents of Streblus asper with potential antineoplastic activity. J Nat Prod 2016; 80(3):648-658.

48. Wongkham S, Laupattarakasaem P, Pienthaweechai K, Areejitranusorn P, Wongkham C, Techanitiswad T. Antimicrobial activity of Streblus asper leaf extract. Phytother Res. 2001;15(2):119-21.

49. Das MK, Beuria MK. Anti-malarial property of an extract of the plant Streblus asper in murine malaria. Trans R Soc Trop Med Hyg. 1991;85(1):40-1.

50. Chatterjee RK, Fatma N, Murthy PK, Sinha P, Kulshrestha DK, Dhawan BN. Macrofilaricidal activity of the stembark of Streblus asper and its major active constituents. Drug Dev Res. 1992;26(1):67-78.

51. Sripanidkulchai B, Junlatat J, Wara-aswapati N, Hormdee D. Anti-inflammatory effect of Streblus asper leaf extract in rats and its modulation on inflammation-associated genes expression in RAW 264.7 macrophage cells. J Ethnopharmacol. 2009;124(3):566-70.

52. Li J, Huang Y, Guan XL, Li J, Deng SP, Wu Q, et al. Anti-hepatitis B virus constituents from the stem bark of Streblus asper. Phytochemistry 2012; 82:100-109.

53. Singsai K, Akaravichien $T$, Kukongviriyapan $V$, Sattayasai J. Protective effects of Streblus asper leaf extract on H2O2-induced ROS in SK-N-SH cells and MPTP-induced Parkinson's disease-like symptoms in C57BL/6 mouse. Evid Based Complement Alternat Med. 2015;2015:970354-9.

54. Prasansuklab A, Meemon K, Sobhon P, Tencomnao T. Ethanolic extract of Streblus asper leaves protects against glutamate-induced toxicity in HT22 hippocampal neuronal cells and extends lifespan of Caenorhabditis elegans. BMC Complement Altern Med. 2017;17(1):551.

55. Iriyama K, Ogura N. Takamiya a. A simple method for extraction and partia purification of chlorophyll from plant material, using dioxane. J Biochem. 1974;76(4):901-4.
56. Mungkornasawakul P, Pyne SG, Jatisatienr A, Supyen D, Lie W, Ung AT, et al. Stemocurtisine, the first pyrido[1,2-a]azapine Stemona alkaloid. J Nat Prod 2003; 66(7):980-982.

57. Marston A, Kissling J, Hostettmann K. A rapid TLC bioautographic method for the detection of acetylcholinesterase and butyrylcholinesterase inhibitors in plants. Phytochem Anal. 2002;13(1):51-4.

58. Taweechaisupapong S, Wongkham S, Chareonsuk S, Suparee S, Srilalai P, Chaiyarak S. Selective activity of Streblus asper on Mutans streptococci. J Ethnopharmacol. 2000;70(1):73-9.

59. Taweechaisupapong S, Singhara S, Choopan T. Effect of Streblus asper leaf extract on selected anaerobic Bacteria. In: ISHS Acta Horticulturae 680: III WOCMAP congress on medicinal and aromatic plants, Vol. 6. Traditional medicine and nutraceuticals; 2005. p. 177-81.

60. Tong SY, Davis JS, Eichenberger E, Holland TL, Fowler VG, Jr. Staphylococcus aureus infections: epidemiology, pathophysiology, clinical manifestations, and management. Clin Microbiol Rev 2015; 28(3):603-661.

61. Zheng CJ, Yoo JS, Lee TG, Cho HY, Kim YH, Kim WG. Fatty acid synthesis is a target for antibacterial activity of unsaturated fatty acids. FEBS Lett. 2005;579(23):5157-62.

62. Asthana RK, Srivastava A, Kayastha AM, Nath G, Singh SP. Antibacterial potential of $\gamma$-linolenic acid from Fischerella sp. colonizing neem tree bark. World J Microbiol Biotechnol. 2006;22(5):443-8.

63. Huang CB, George B, Ebersole JL. Antimicrobial activity of $n-6, n-7$ and $n-9$ fatty acids and their esters for oral microorganisms. Arch Oral Biol. 2010;55(8):555-60

64. Desbois AP, Lawlor KC. Antibacterial activity of long-chain polyunsaturated fatty acids against Propionibacterium acnes and Staphylococcus aureus. Mar Drugs. 2013;11(11):4544-57.

65. Smith MA, Rottkamp CA, Nunomura A, Raina AK, Perry G. Oxidative stress in Alzheimer's disease. Biochim Biophys Acta. 2000;1502(1):139-44.

66. Gadidasu K, Reddy ARN, Umate P, Reddy YN. Antioxidant and anti-diabetic activities from leaf extracts of Streblus asper Lour. Biotechnol Ind J. 2009;3(4):231-5

67. Ibrahim NM, Mat I, Lim V, Ahmad R. Antioxidant activity and phenolic content of Streblus asper leaves from various drying methods. Antioxidants (Basel). 2013;2(3):156-66.

68. Kumar RS, Kar B, Dolai N, Bala A, Haldar PK. Evaluation of antihyperglycemic and antioxidant properties of Streblus asper Lour against streptozotocininduced diabetes in rats. Asian Pac J Trop Dis. 2012;2(2):139-43.

69. Kumar RB, Kar B, Dolai N, Karmakar I, Haldar S, Bhattacharya S, et al. Antitumor activity and antioxidant role of Streblus asper bark against Ehrlich ascites carcinoma in Swiss albino mice. J Exp Ther Oncol 2013; 10(3):197-202.

70. Kumar RB, Kar B, Dolai N, Karmakar I, Bhattacharya S, Haldar PK. Antitumor activity and antioxidant status of Streblus asper bark against Dalton's ascitic lymphoma in mice. Interdiscip Toxicol. 2015;8(3):125-30.

71. Lachman J, Šulc M, Schilla M. Comparison of the total antioxidant status of bohemian wines during the wine-making process. Food Chem. 2007;103(3):802-7

72. Floegel A, Kim D-O, Chung S-J, Koo SI, Chun OK. Comparison of ABTS/DPPH assays to measure antioxidant capacity in popular antioxidant-rich US foods. J Food Compost Anal. 2011;24(7):1043-8.

73. Craig LA, Hong NS, McDonald RJ. Revisiting the cholinergic hypothesis in the development of Alzheimer's disease. Neurosci Biobehav Rev. 2011;35(6):1397-409.

74. Tan S, Schubert D, Maher P. Oxytosis: a novel form of programmed cell death. Curr Top Med Chem. 2001;1(6):497-506.

75. Sheldon AL, Robinson MB. The role of glutamate transporters in neurodegenerative diseases and potential opportunities for intervention. Neurochem Int. 2007:51(6-7):333-55.

76. Kritis AA, Stamoula EG, Paniskaki KA, Vavilis TD. Researching glutamate - induced cytotoxicity in different cell lines: a comparative/collective analysis/study. Front Cell Neurosci. 2015;9:91. 